\title{
Presenting an Innovative Approach Combining FA and ANP Methods to Identify and Prioritize Water Pollutants in Petroleum and Petrochemical Industries
}

\author{
Abolfazl Rohani \\ Department of Industrial Engineering \\ Payam Nour University (PNU), Iran \\ and \\ School of Industrial Engineering, College of Engineering \\ University of Tehran, Tehran, Iran
}

\begin{abstract}
Abbas Keramati
School of Industrial Engineering, College of Engineering Alborz Campus

University of Tehran, Tehran, Iran

Jafar Razmi

School of Industrial Engineering, College of Engineering Alborz Campus University of Tehran, Tehran, Iran
\end{abstract}

\begin{abstract}
Water contamination is one of the important challenges and problems of the world and Iran. One of the main causes of disease and mortality in the world is water contamination. Surface and groundwaters are both subject to different contaminants. Considering the nature, origin of entrance of the pollutants, being natural or man-made, various classifications have been considered for contaminants. The major organic contaminants of water include agricultural, chemical, oil, and food contaminants. Each of these four groups has subcriteria. In this research, accurate investigation, identification, and ranking of water contaminants it all oil and petrochemical industries (urban area of Tehran province) have been dealt with using factor analysis and analytical network process methods. The results of factor analysis method suggest that the contaminants of nitrate, sodium, and TDH claimed the highest score by experts of environment in the field of water contamination. Furthermore, the results of analytical network process showed that agricultural contaminants with the weight of 0.321 stood in the first rank, while oil contaminants with the weight of 0.152 ranked the fourth.
\end{abstract}

Keywords: water contaminants, analytical network process, principal component analysis, factor analysis, oil and petrochemical industry

\section{INTRODUCTION}

Today as the demand market has become something central, it has resulted in development of the significance of supply chain such that it has changed into one of the vital instruments in commercial competitions. On the other hand, environmentalism has changed into an important commercial- social issue. Considering the significance of these two issues, green chain concept was developed and has attracted the attention of pioneering companies across the global competition. Today, the managers of leading companies try to benefit from improving their 
environmental performance throughout the entire supply chain as a strategic weapon for gaining competitive advantage through developing utility and satisfaction throughout the entire supply chain (Razmi and Nasrollahi, 1392). Furthermore, the environment that has surrounded the human and allowed him to leave has been threatened by the human itself. Today, we live in a world in which the plight of environmental contamination due to the rapid growth of population, industry, and constraint of natural resources has become of interest to scientists and experts more than ever it has also been paid attention to by the public as a tangible issue. In today's societies, the significance of environmental protection seems to be something essential and evident. Undoubtedly, conducting and implementing any program requires sufficient knowledge and essential understanding of the environment and its contaminants. Currently, the environmental crises caused by the contaminations is threatening many countries seriously. Therefore, countries can control these environmental crises through serious and logical protection of their environment and scientific programs. In this regard, recognizing water contamination and the industries that develop these contaminations has facilitated the way to combating such contaminations (Ramudhin et al, 2010).

Tom Buchert et al (2015) presented development of sustainable product- advantages and obstacles in a research called multicriteria decision-making as an instrument for. In that paper, they merged discrete decision-making trees with lifecycle sustainability assessment (LCSA) for development of multi-criteria quantitative analysis. Further, to improve decision-making they have presented an integrated method for designing sustainable product. The main objective of the selected approach is covering the gap between prospective and retrospective decisionmaking through quantitative analysis in the preliminary stages of design. The final outcome of this research suggests that for developing sustainable products, design engineers can benefit from multi-criteria quantitative sustainable information which is currently available in the preliminary stages of product design. In another research, Cozzi et al dealt with spatial assessment for agriculture with the aim of increasing the productivity in terms of econometrics in Italy. In this research, which has been done in Basilicata region in Italy, for filtering the refuse resulting from chemical wastes, weighted average method has been used along with verbal quantifier. Accordingly, a suitable map for decreasing the products of a country which was far from chemical wastes and especially water wastes was recognized across the studied region. Based on geological and agricultural scales used in this research, the researchers found that out of the entire studied region, only 25 hectares of the 163 available hectares are cultivable. Furthermore, the results of this research confirmed the fact that if entrance of chemical wastes and especially the water contaminants are not prevented from being introduced into groundwaters of agricultural regions, these regions will be on the verge of devastation.

However, Lam and Dai (2015) used a combinational method of developing the quality performance and analytical network process for optimizing the providers of logistics to improve sustainability of green supply chain in order to lower water contaminants. In that research, they concluded that the most important determining factor of sustainability is economic and environmental issues (water contaminants). Martijn Bouwknegt et al (2015) assessed the hazards threatening production of fresh crops despite its green leaves throughout its supply chain in Europe. In that research, based on the studies on a wide range of environmental contaminants and especially water contaminants, they found that there threatening hazards are not merely a general health risk by viruses in foods which are important in supply-chain. Further, they cannot be coped with only through identification and evaluation of viruses in retail products. Accordingly, presentation of a solution in this regard is crucial. In this research, using a conceptual model earned through investigating the indices 
affecting the quality of agricultural crops including the level of water contaminants such as phenol, nitride, ammonium, and the nitrate present in some foods cultivated close to chemical industries in several points of the member countries of the European Union, the negative effect of these contaminants on the quantity of products has been observed abundantly. The results of research on several specific products such as lettuce and soft fruits such as strawberry, in contaminated regions, when compared with cleaned regions, the quantity of these crops had a drop in quality by $97.5 \%$ and this reduction in the quality is due to liberating the contaminants of the current chemical industries in the region to agricultural farms.

The structure of this paper is as follows: Sections 2 and 3 deal with the significance and necessity of water resources and the present research. Section 3 deals with the methodology. In Section 4, the stages of the research are dealt with. Statement of the introduction of the effective criteria and subcriteria in the assessment process has been thoroughly discussed in Section 5. Eventually, Section 6 states the conclusion of the research.

\section{THE SIGNIFICANCE AND NECESSITY OF PROTECTING WATER RESOURCES}

Water is one of the most abundant compounds which is found in the nature and occupies almost $75 \%$ of the earth surface. However, several factors have contributed to water shortage across the world. The first factor is heterogeneous geographical distribution; over $97 \%$ of the entire water resources are found in oceans and seas, where due to the high level of soluble salts, they are not suitable for direct consumption (Alaimo, Peter \& Amanda-Lynn Marshall). Over $2 \%$ of the entire water resources are present in glaciers and Polar Regions or are found as humidity in the soil and the earth's atmosphere. Due to unavailability, planning for using them is not justifiable in terms of economic feasibility. Thus, for survival and meeting industrial, agricultural, and drinking purposes, human beings can have access to only $62 \%$ of the water remain in the lakes, rivers, and groundwaters. This not only has reduced the quality of available water resources and brought about further limitations, but the resources have also faced decreased and altered quality of waters due to development of urbanization and industrial as well as agricultural activities. It is many years that it is investing in proper planning of management of water resources (Azadfallah, M., \&Azizi).

\section{THE ENVIRONMENT AND ENVIRONMENTAL CONTAMINATIONS AND THE SIGNIFICANCE OF THE RESEARCH}

The environment refers to all environments in which life exists. A set of external physical factors and living creatures which are interacting with each other constitute the environment and influence the growth and behavior of creatures. Environmental protection in the 21st century is known as one of the eight objectives of the millennial development and one of the three pillars of sustainable development (Azadi et al, 2015). Natural environment is a combinational term from different sciences, which involves a set of biological and environmental factors in the form of environment and non-biological factors (physical, chemical) which influence the life of a person or species and are also influenced by them. Today, this definition is mainly related to human beings and their activities, where the environment can be summarized as a set of the natural agents of the earth such as air, water, atmosphere, rocks, plants, etc. which are surrounding the human. The difference between the environment and nature lies in the fact that definition of nature involves a set of natural, biological, and non-biological factors which are considered exclusively, while the term "environment" has been described based on the interactions between human and nature and according to their viewpoint (Lam and Dai, 2015).

The characteristic of the environment of modern business is ever increasing competition and economic globalization. Under such conditions, producers benefit from novel the strategies and 
technologies to achieve the environment. Therefore, throughout the recent years, supply-chain management 3 has attracted the attention of both academics and industries as an effective business philosophy (Pishvaee \& Razmi, 2012). As green supply-chain methods 5 have developed a green revolution across the supply chain, companies should use their internal and external resources to implement the green supply-chain methods.

Contamination of water and underground resources with different contaminants brings about various environmental negative effects. The contamination caused by industrial activities has always brought concern for industry stakeholders and the Institutes supervising the environment. Selecting adaptive policies and logical solutions for cleaning the environment in a way congruent with environmental considerations is inevitable. Considering the effect of environment in the life and in turn human survival, protecting the environment is considered something essential. Therefore, to achieve this aim, recognition of the issues that contribute to environmental contamination seems to be evident, as the country has many industrial towns (production industries), thus understanding and being aware of the factors influencing environmental contaminations are considered to be important. Through this, these factors can be mitigated and for eliminating them some important measures can be taken to protect the environment. As water is not a consumer and worthless product. Today, water is a strategic and economic good which is very valuable and those who own it have bargaining power and are able to disturb political and regional equations. Furthermore, water shortage in dry and semidry regions, on the one hand, and wasteful and wrong consumption of water resources and their contamination on the other are serious threats for sustainable development and environmental protection.

Based on the points mentioned above and according to the previous studies, we achieved a study gap and absence of an efficient method for identification and prioritization of a variety of water contaminations in green supply-chain. Based on this fact, in this research attempts have been made to present a method with expert system design for identifying and prioritizing a variety of water contaminations in green supply-chain as an instrument for responding to the needs of the target population. Briefly, the novelties of this research include:

- in this research, it is predicted that major contaminants and their level in the Iranian oil and petrochemical industry and especially Tehran province are extracted and after presenting a mathematical model with the aim of decreasing environmental contaminants and presenting it to the relevant organizations, an effective step is taken towards preventing devastation of the environment of the development of contaminants this industry.

- As Iran is an oil-rich country and has many refineries and petrochemical industries along with relevant industries, the results of the above-mentioned plan can be used in these industries and other similar areas.

\section{STAGES OF THE PROCEDURE OF THE RESEARCH}

In this research, the methodology is of applied type, in terms of objective, while in terms of type, it is an assessment method based on questionnaire analysis in the real world; it can be put forward as a case study. Determining the input and output indices, obtaining and extracting the variables in this type of research itself are important parts of implementation of this research. The following steps were taken:

- Determining the criteria through the research background and PCA method

- Development of questionnaire

- Examining the reliability of the questionnaire

- Data collection 
- Determining the validity of the items of the collective questionnaires

- Giving weights to the variables

- Analysis and ranking using ANP method

\section{Principal component analysis (PCA)}

Principal component analysis is one of the classic multivariate methods and perhaps their oldest and most famous method. This method was first developed to analyze the structure of variance-covariance matrices and correlation coefficient. As with many multivariate methods, prior to invention of computers, this method was not widely used due to complexity of calculations. Thereafter, in terms of theory and application, it was widely developed and employed. This type of analysis can be focused on from several perspectives.

- Conversion of dependent variables to uncorrelated variables

- Finding linear combinations with large or small relative variability

- Reduction of the volume of data

- Data interpretation

This type of analysis is not usually considered a final analysis, rather it is mainly used as an intermediate tool for further studies and investigations. The mathematical aspects used in this research involved eigenvalues and the Eigen vectors of symmetrical always positive matrices. Reduction of the volume of data is the main objective of this analysis, where these data consist of a large number of variables with internal correlations, such that the maximum available information possible in the data is kept. This takes place through converting the data (variables) to new variables which are called principal component and are uncorrelated. They are prioritized in an order that a small number of them often bring the changes in the initial variables with them. In the analysis of principal component, although seemingly the main focus is on the variance of variables, considering the relationships between the variances and covariance's, this method also takes covariances or correlation coefficients into consideration implicitly.

\section{Analytical network process (ANP)}

Saati (1996) presented a method for multi-criteria decision-making. This method is called analytical network process (ANP) which has the aim of developing a model through which complex multi-criteria decision-making problems are analyzed into smaller components and through logical initialization they are converted to simpler components and finally combination of these values help in final decision-making. ANP method is the developed form of AHP method which is able to model the correlations and feedbacks between the elements affecting a decision-making and can take all internal effects of the effective components in decision-making into consideration and introduce them into the calculations. Therefore, with the help of this characteristic, this technique is superior then the previous relevant models. Indeed, it can be stated that AHP is a special form of ANP method. ANP method has two main parts, which combines these two parts in a process. The first part involves groups consisting of controlling criteria and subcriteria as well as the group which takes the options of the volunteer. The second part is a network of vectors and arcs which represent the dependencies and correlations and the feedbacks present in the decision-making system. Eventually, this method is based on conducting paired comparisons which is similar to the paired comparisons performed in AHP method. Analytical network process can be called the most complete multicriteria decision-making method which has been presented so far. However, the single important problem in this model is performing paired comparisons. This problem which also exists in AHP method is considered problematic as a decision-maker is not always facing accurate states of commenting and in many decision-makings of the real world, the decision- 
makers cannot make decisions about paired comparisons with certainty. The modeling process involves the following stages:

- The first step, basing the model and structure of the problem

- The second step, paired comparisons matrix and estimation of the relative weight

- The third step, development of the preliminary super matrix

- The fourth step, development of weighted super matrix

- The fifth step, calculation of the general weighted vector

- The sixth step, calculation of the final weight of the criteria

\section{INTRODUCTION OF THE INFLUENTIAL CRITERIA AND SUBCRITERIA IN THE EVALUATION PROCESS}

In this research, by presenting a framework, to identify and prioritize the extent of greenness of production industries and presentation of a solution for enhancing the greenness of supply chain. According to the background and interview with experts, the criteria effective in the evaluation process have been developed as the steps presented in the research according to Fig. 1. In this model, the aim is identification and prioritization of industrial contaminants in water (wastewater) which lies at level I. the production industries which include food industries, chemical industries, agriculture industries, and oil industries in two petrochemical and refineries of the oil in Tehran have been shown at Level II, which are in the form of nitrate (NO3), nitride (N3-), and ammonium (NH3) present in food industries, phosphate (PO4), sulfate (SO4), and chloride (Cl-) present in chemical industries, phenol (C6H5OH), sulfide (H2S), oil, mercury (Hg), and cadmium (Cd) present in oil industries, and nitrate (NO3), ammonium (NH3), phosphate (PO4), and chloride (Cl-) present in agricultural industries, which are considered as subcriteria. BOD, COD, TDS, and TSS which are known as comparative evaluation indices of contaminants across all production industries are considered as the subcriteria at Level III. Finally, these contaminants are prioritized in industry in the order of contamination in the environment. The list of the contaminants includes the following (Cozzi et al, 2015):

\section{Introduction of the criteria that detect the contaminants}

- Biochemical oxygen demand (BOD): oxygen consumption rate inside water by organisms. If BOD is low, water is clean and lacks any organism or the organisms inside water are dead and have no need to consume oxygen. BOD is the amount of oxygen required for biological stability in water. The size of facilities of biological treatment especially the wastewater aeration rate in aeration basins can be calculated by BOD level. If water BOD is $1 \mathrm{ppm}$, then the water is almost pure. Water with a BOD up to 5 ppm is considered to be relatively pure, but when it exceeds 5 ppm, purity of water is questioned. However if its value goes beyond $20 \mathrm{ppm}$, the public health is jeopardized. BOD experiments provide a realistic estimation of the quality of oxygen that has been introduced into the water (Bouwknegt et al, 2015).

- Chemical oxygen demand: it is the amount of oxygen that is required so that the organic compounds present in the sample are chemically stabilized. The utilized oxidizer is usually potassium dichromate in the presence of sulfuric acid. Wastewater contamination caused by the external compounds that enter water as suspended or soluble form, cause its contamination and production of wastewater. Evidently, the higher the level of these compounds in wastewater, the greater its contamination load. Therefore, measurement of the amount of external compounds of wastewater is the major key in determining the extent of contamination of wastewater (Liu et al, 2011).

- Total dissolved solids or concentration of minerals: it is the amount of organic compounds or mixed inside a liquid, where these compounds can exist in water as 
molecular or ionized form or very tiny grains at micron level as a suspended form. The primary resources (major applications) for TDS in receiving waters, the waters resulting from agriculture and residential areas, soil contamination washing and the contaminated water resources discharged from industrial units and wastewaters. The most important aspect of TDS, taking water quality into consideration, is its effect on the taste of water. Clarity and transparency of water with a TDS lower than $600 \mathrm{mg} / \mathrm{l}$ is generally considered a good state. Drinking water with a degree above $1200 \mathrm{mg} / \mathrm{l}$ is considered an unfavorable state by the majority of consumers. The difference between TDS and TSS lies in the fact that in TSS the particles cannot pass through a filter with a 2-micron scale and remain suspended in the solution for an unknown time (Mulberry et al, 2010).

\section{Classification of water contaminants}

The processes for selecting the selection criteria of the extent of contamination of industries are based on the two following areas:

- Investigation of the criteria used by previous researchers

- Study of the contamination indices and important contaminating industries according to managers and experts of environment

Based on the mentioned process, a set of the most important selection indices of industries and contaminants were considered as the main measurement criteria.

1. The criterion of contamination of food industries: Based on the extent of significance and development of these contaminants in groundwaters, the criterion of food industries consists of three subcriteria of "nitrate", "phosphorus", and "protein" (Zhang et al, 2013).

2. The criterion of contamination of chemical industries: The four following criteria are considered the most important subcriteria of the characteristics of this industry in laboratory trusted by the environment, which have been selected at this stage: lead, mercury, copper, alkalinity of suspended solids and heavy metals (Wu et al, 2012).

3. The criterion of contamination of oil industries: the following subcriteria are among the most important ones of this industry in measuring the extent of contamination: phenol, hydrogen sulfide, oil, ammonium, and TPH (Zailani et al, 2015).

4. The criterion of contamination of agricultural industries: furthermore, the following criteria have been considered as the subcriteria associated with agricultural industries: nitrate, chemical fertilizers, sediments, and TOG (Yongming et al, 2006).

Fig. 1. Represents the major contaminants by individual types.

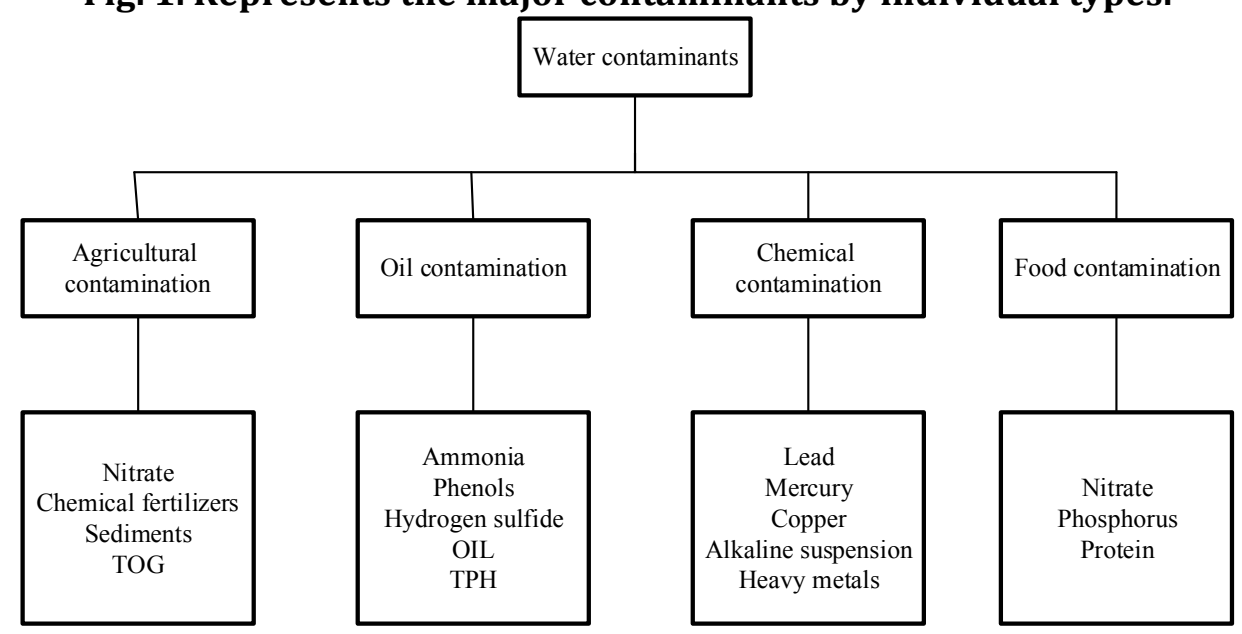

Fig. 1. Classification of the contaminants 


\section{RESULTS}

Next comes explanation of the results of the open-ended questionnaire and analytical network process method.

\section{Statistical analysis}

According to the previous studies, 20 water contaminant indices were extracted and then distributed among 145 experts, so that based on their previous background, a score between 1 (the least significant) and 10 (the most significant) would be given. Accordingly, for ranking the contaminants, statistical methods and especially factor analysis and PCA were used. Then, we deal with explanation of the results of the open-ended questionnaire. Tables 1-3 present the preliminary factor analysis of the indices for estimating the contributing performance of each of the contaminants on the problem's objective.

Table 1. The ratio of the variance of each of the contaminants

\begin{tabular}{|c|c|c|}
\hline \multicolumn{3}{|c|}{ Communalities } \\
\hline & Initial & Extraction \\
\hline Nitrate & 1.000 & .783 \\
\hline phosphor & 1.000 & .671 \\
\hline PH & 1.000 & .667 \\
\hline OIL & 1.000 & .667 \\
\hline TDS & 1.000 & .712 \\
\hline heavy metals & 1.000 & .579 \\
\hline TSS & 1.000 & .559 \\
\hline Ammonia & 1.000 & .599 \\
\hline Phenols & 1.000 & .532 \\
\hline Protein & 1.000 & .491 \\
\hline Chemical fertilizers & 1.000 & .627 \\
\hline COD & 1.000 & .591 \\
\hline Sediments & 1.000 & .712 \\
\hline Hydrogen sulfide & 1.000 & .684 \\
\hline Lead & 1.000 & .708 \\
\hline Mercury & 1.000 & .725 \\
\hline Copper & 1.000 & .726 \\
\hline DO & 1.000 & .572 \\
\hline BOD & 1.000 & .472 \\
\hline
\end{tabular}

Table 1 provides the ratio of the variance of the scores taken by each contaminant by the experts. As can be observed in the table, the contaminants nitrate, sodium, and TDS have claimed the highest score by the experts of environment regarding water contamination.

Table 2 presents the frequency distribution of the sum of the variance of contaminants. In this table, the results were investigated based on PCA method. In the above table, Initial eigenvalues column represents the variance associated with the complete set of contaminants from the initial results. Furthermore, the column of extraction sums of squared loadings demonstrate the variance of the most important contaminants among all the contaminants. 
Table 2. The sum of distributional variance of the contaminants

\begin{tabular}{|c|c|c|c|c|c|c|}
\hline \multicolumn{7}{|c|}{ Total Variance Explained } \\
\hline \multirow{2}{*}{ Component } & \multicolumn{5}{|c|}{ Initial Eigenvalues } & \multicolumn{1}{|c|}{ Extraction Sums of Squared Loadings } \\
\cline { 2 - 7 } & Total & \% of Variance & Cumulative \% & Total & \% of Variance & Cumulative \% \\
\hline $\mathbf{1}$ & 1.759 & 9.257 & 9.257 & 1.759 & 9.257 & 9.257 \\
\hline $\mathbf{2}$ & 1.621 & 8.533 & 17.789 & 1.621 & 8.533 & 17.789 \\
\hline $\mathbf{3}$ & 1.529 & 8.049 & 25.839 & 1.529 & 8.049 & 25.839 \\
\hline $\mathbf{4}$ & 1.392 & 7.325 & 33.163 & 1.392 & 7.325 & 33.163 \\
\hline $\mathbf{5}$ & 1.374 & 7.234 & 40.397 & 1.374 & 7.234 & 40.397 \\
\hline $\mathbf{6}$ & 1.178 & 6.199 & 46.596 & 1.178 & 6.199 & 46.596 \\
\hline $\mathbf{7}$ & 1.142 & 6.013 & 52.609 & 1.142 & 6.013 & 52.609 \\
\hline $\mathbf{8}$ & 1.078 & 5.672 & 58.281 & 1.078 & 5.672 & 58.281 \\
\hline $\mathbf{9}$ & 1.000 & 5.266 & 63.546 & 1.000 & 5.266 & 63.546 \\
\hline $\mathbf{1 0}$ & .970 & 5.103 & 68.649 & & & \\
\hline $\mathbf{1 1}$ & .898 & 4.728 & 73.377 & & & \\
\hline $\mathbf{1 2}$ & .857 & 4.509 & 77.886 & & & \\
\hline $\mathbf{1 3}$ & .811 & 4.267 & 82.153 & & & \\
\hline $\mathbf{1 4}$ & .739 & 3.890 & 86.043 & & & \\
\hline $\mathbf{1 5}$ & .667 & 3.511 & 89.554 & & & \\
\hline $\mathbf{1 6}$ & .610 & 3.209 & 92.763 & & & \\
\hline $\mathbf{1 7}$ & .523 & 2.750 & 95.513 & & & \\
\hline $\mathbf{1 8}$ & .469 & 2.471 & 97.984 & & & \\
\hline $\mathbf{1 9}$ & .383 & 2.016 & 100.000 & & & \\
\hline & & Extraction Method: Principal Component Analysis. & \\
\hline
\end{tabular}

Table 3. The correlation matrix between each of the contaminants

\begin{tabular}{|c|c|c|c|c|c|c|c|c|c|}
\hline \multicolumn{10}{|c|}{ Component Matrix(a) } \\
\hline & \multicolumn{9}{|c|}{ Component } \\
\hline & 1 & 2 & 3 & 4 & 5 & 6 & 7 & 8 & 9 \\
\hline TSS & -.583 & .098 & .315 & .224 & .149 & .011 & .181 & .057 & .046 \\
\hline TDS & .572 & -.169 & .230 & .350 & .044 & .000 & -.056 & -.416 & -.046 \\
\hline Lead & .534 & -.087 & .248 & -.086 & -.303 & -.040 & .035 & .270 & -.423 \\
\hline Chemical fertilizers & .070 & .566 & -.202 & .171 & .043 & -.031 & .003 & -.432 & -.204 \\
\hline heavy metals & .213 & -.503 & .260 & -.230 & .278 & -.149 & .183 & -.077 & .149 \\
\hline Ammonia & .365 & .488 & .227 & -.112 & .088 & .253 & \begin{tabular}{|l|l|}
3 & -.048 \\
\end{tabular} & .300 & -.009 \\
\hline Sediments & .126 & .138 & -.674 & .185 & .150 & .217 & 7.243 & .029 & .244 \\
\hline Mercury & -.215 & .205 & .472 & .187 & -.392 & .307 & 7.042 & -.343 & .103 \\
\hline Phenols & .104 & .327 & .275 & .379 & .275 & .299 & .041 & .147 & -.077 \\
\hline BOD & .362 & .040 & -.095 & .375 & .246 & .001 & \begin{tabular}{|l|l|}
109 \\
\end{tabular} & .085 & .331 \\
\hline Copper & -.215 & -.314 & .110 & -.170 & .525 & .319 & \begin{tabular}{|l|}
9 \\
\end{tabular} & -.061 & -.312 \\
\hline DO & .158 & -.202 & .291 & .404 & .432 & -.156 & $5-.156$ & 5.065 & .137 \\
\hline COD & -.124 & -.350 & -.055 & .358 & -.383 & -.206 & 5 & $7-.123$ & .227 \\
\hline Nitrate & .131 & .112 & .283 & .044 & -.030 & -.402 & 2.712 & -.039 & -.012 \\
\hline phosphor & .198 & .348 & .174 & -.172 & -.178 & -.300 & -.561 & .005 & .120 \\
\hline OIL & -.179 & -.235 & .170 & .344 & -.382 & .321 & .022 & .422 & .070 \\
\hline Protein & .033 & .053 & -.250 & .312 & -.019 & -.356 & \begin{tabular}{|l|} 
\\
\end{tabular} & .414 & -.170 \\
\hline Hydrogen sulfide & .414 & -.098 & .016 & -.360 & -.156 & .363 & 3.124 & .022 & .447 \\
\hline PH & -.269 & .362 & .305 & -.257 & .217 & -.276 & -.078 & .153 & .390 \\
\hline \multicolumn{10}{|c|}{ Extraction Method: Principal Component Analysis. } \\
\hline & & & & & & & & & \\
\hline
\end{tabular}


Table 3 indicates the correlation matrix between all of the contaminants with nine selected contaminants which had the greatest contamination variance as commented by experts according to Table 2. Based on the results of this table, all of these contaminants have a low correlation with each other.

Table 4. The final ranking of the contaminants according to expert comments

\begin{tabular}{ccc}
\hline Final Ranking & Score & contaminants \\
\hline 2 & 0.955 & Nitrate \\
\hline 10 & 0.734 & phosphor \\
\hline 13 & 0.808 & PH \\
\hline 15 & 0.719 & OIL \\
\hline 12 & 0.711 & TDS \\
\hline 11 & 0.726 & heavy metals \\
\hline 12 & 0.729 & TSS \\
\hline 3 & 0.726 & Ammonia \\
\hline 14 & 0.83 & Phenols \\
\hline 16 & 0.717 & Protein \\
\hline 7 & 0.707 & Chemical fertilizers \\
\hline 8 & 0.764 & COD \\
\hline 14 & 0.754 & Sediments \\
\hline 1 & 0.717 & Hydrogen sulfide \\
\hline 17 & 0.97 & Lead \\
\hline 6 & 0.703 & TOG \\
\hline 5 & 0.785 & Mercury \\
\hline 9 & 0.788 & Copper \\
\hline 17 & 0.743 & DO \\
\hline 4 & 0.703 & BOD
\end{tabular}

As can be observed in Table 4, Lead contaminants is considered the most important water contaminant by the experts. It is followed by nitrate with the score of 0.955 , as the second rank. Furthermore, in the above table it can be deduced that several contaminants had the same score according to the experts, which include hydrogen sulfide and heavy metals, both of which had a score equal to 0.717 .

\section{Analytical Network Process}

In order to achieve the objective of the research, paired comparisons questionnaires were designed and distributed among the experts. Considering the verbal judgment approach in this research, the statements and numbers written in Table 5 were used.

Table 5. The defined numbers

\begin{tabular}{cc}
\hline relative comparison of the indices (verbal judgment) & Priority number \\
\hline Absolute significance & 9 \\
\hline Very strong significance & 7 \\
\hline Strong significance & 5 \\
\hline Weak significance & 3 \\
\hline Equal significance & 1 \\
\hline Intermediate values & $2,4,6,8$
\end{tabular}

In this section, based on the hierarchical network, the prepared paired comparisons tables and the modified method of Asgharpour et al (1388), the weight of the components was obtained and they were then prioritized. The results were calculated by Super Decision software.

In this research, ANP technique was used for determining the priority of objectives. For this purpose, using ANP questionnaire, 15 (Wibisono, D., \& Khan) managers and experts of the field of environment related to oil and petrochemical contaminants were requested to give their comments. Thereafter, the data written in the matrices were analyzed by Excel and Super 
Decision software applications. Based on them, the inconsistency rate was obtained to be 0.04 . As this rate is lower than 0.1 , then the obtained weights are reliable. Next, the results obtained from the analytical network process are explained in detail.

Table 6. Ranking of the major criteria

\begin{tabular}{ccc}
\hline The main criterion & weight & rank \\
\hline agricultural contaminants & 0.321 & 1 \\
\hline chemical industries & 0.286 & 2 \\
\hline oil contaminants & 0.152 & 4 \\
\hline food industries & 0.241 & 3
\end{tabular}

Table 6 represents the ranking of the major criteria of water contaminants. As can be observed in the table, agricultural contaminants (weight $=0.321$ ) and oil contaminants (weight $=0.152$ ) stand in the first and fourth rank, respectively. Next, in Tables 7-10, the ranking of the subcriteria of the contaminants of each of the four major criteria is presented.

Table 7. The ranking of this sub-criteria of food contaminants

\begin{tabular}{ccc}
\hline The main criterion & weight & rank \\
\hline Nitrate & 0.455 & 1 \\
\hline Phosphorus & 0.431 & 2 \\
\hline Protein & 0.114 & 3
\end{tabular}

The results of Table 7 indicate that the nitrate element claimed the first rank in the subcriteria of food contaminants. Furthermore, this result confirms the first section of the research in the open-ended questionnaire, as the majority of experts had chosen this element as the second important contaminant.

Table 8. Ranking of the sub-criteria of agricultural contaminants

\begin{tabular}{ccc}
\hline The main criterion & weight & rank \\
\hline nitrate & 0.287 & 1 \\
\hline chemical fertilizers & 0.255 & 2 \\
\hline sediments & 0.215 & 3 \\
\hline TOG & 0.243 & 4
\end{tabular}

The results of Table 8 indicate that the nitrate element lies in the first rank among the subcriteria of agricultural contaminants. As was stated in the results of this subcriteria of food contaminants, this result confirms the first section of the research in the open-ended questionnaire, as the majority of experts had chosen this element as the second contaminant.

Table 9. Ranking of the sub-criteria of chemical contaminants

\begin{tabular}{ccc}
\hline The main criterion & weight & rank \\
\hline alkalinity of suspended solids & 0.155 & $\mathbf{4}$ \\
\hline Heavy metal & 0.096 & $\mathbf{5}$ \\
\hline lead & 0.382 & $\mathbf{1}$ \\
\hline mercury & 0.166 & $\mathbf{3}$ \\
\hline copper & 0.201 & $\mathbf{2}$ \\
\hline
\end{tabular}

Table 9 represents the results of ranking the subcriteria of chemical contaminants. As can be observed, lead with the weight of 0.382 is standing in the first rank of these subcriteria. As had been shown in Table 4, the lead element was considered the most important contaminant by the experts in the field of oil and petrochemical industries. 
Table 10. The ranking of the sub-criteria of oil contaminants

\begin{tabular}{ccc}
\hline The main criterion & weight & rank \\
\hline oil & 0.160 & $\mathbf{4}$ \\
\hline TPH & 0.198 & $\mathbf{2}$ \\
\hline ammonium & 0.301 & $\mathbf{1}$ \\
\hline hydrogen sulfide & 0.188 & $\mathbf{3}$ \\
\hline phenol & 0.143 & $\mathbf{5}$ \\
\hline
\end{tabular}

Table 10 represents the results of ranking the subcriteria of oil contaminants. As can be observed, ammonium with their weight of 0.301 claims the first rank in these subcriteria. It is followed by TPH and hydrogen sulfide with respective weights of 0.198 and 0.188 .

\section{CONCLUSION}

Many of the rivers in the country such as Karoun, Zayandehroud, and Sefidrood are challenging with both quantitative problems and devastation of the quality of water resources. Gas stations and underwater reservoirs of storage of oil products and derivatives, due to not performing the necessary monitory and the decay of their walls, are regularly contaminating the environment and especially groundwater resources. In the majority of Iranian villages, household wastewaters are present at the level of avenues and open warehouses or are discharged through absorption wells. This type of discharge of wastewaters has caused contamination of surface and groundwater resources. Furthermore, the leachates caused by livestock waste which contains large amounts of nitrogen and micro creatures, contaminates water resources. Typically, these contaminating sources are also pathogenic. By limiting the origin of water contaminants, the quality of water resources can be improved significantly. Use of detergents in a controlled way and at the required level, limitation of usage of chemical fertilizers, pesticides, and insecticides, and not discharging oil contaminants onto impermeable grounds and running water resources can significantly prevent entrance of contaminants to water systems. Further, the place of the living and grazing of local live stocks should be as far from water resources as possible, so that entrance of their wastes into surface waters is prevented. The wastewater of industries, small stores, restaurants, and canteens contain large amounts of organic and inorganic contaminants which should not be discharged into rivers and seas directly and without treatment.

As was indicated in Table 4, lead contaminant is the most important water contaminant according to experts. This element is followed by nitrate with the score of 0.955 . Furthermore, in this table it can be deduced that several contaminants had the same score according to the experts, which include hydrogen sulfide and heavy metals, both of which had a score of 0.717 .

In future research, other probabilistic modeling approaches can be used or with a combinational approach, fuzzy systems and artificial intelligence can also be employed, and the results can then be compared with each other. Furthermore, it is possible to benefit from robust approach to allocate and correspond with uncertainty.

- Use of Z-numbers calculations in the investigational variables

- further, as the waste water from chemical processes of companies is considerable and environmental contamination is also an issue for the organization of environment, if these contaminations exceed a certain environmental determined level, it will lead to considerable fines, thus for future research, the factor of air pollution can also be added to the problems and the results can be investigated. 
- Placing septic tank 1 for wastewater and hen transference of the contents to remote and safe areas or retreat ability of these wastewaters. These processes can be compared with the current environmental implications and the results can also be investigated.

- Integration of the strategic decisions with tactical/operational decisions. For example, in the issue of management of industrial wastewaters and emission of greenhouse gases, the presented suggested models can result in saving on the up to a certain level. A greater level of saving can be accompanied by strategic and large-scale decisions such as construction of treatment systems or to ideological development of construction processes. On the other hand, other strategic decisions such as construction of new production companies and suppliers can also be very interesting.

- Development of other heuristic and metaheuristic methods for multi-objective optimization problems under uncertainty conditions with large-scale

- Problem modeling by considering other objectives such as minimizing the change across the human workforce, minimizing emission greenhouse gases and industrial wastes

- Modeling the problem as a hierarchy and comparing its strong and weak points with an integrated approach

- modeling in a decentralized form and comparing its weak and strong points, in relation with a centralized approach (in the proposed models, all tactical and operational decisions have been modeled by the main company and by considering the profit and loss of the entire chain in a centralized form, the decentralized approach can be taken in a way that in the supply chain, each company is program individually such that it is able to both optimize its program and in a multiparty game of the entire chain, moves towards the total optimum).

\section{References}

1. A. Ramudhin, A. Chaabane, M, Paquet (2010),. "Carbon market sensitive sustainable supply chain network design", International Journal of Management Science and Engineering Management 5(1). 30-38.

2. Asgharpour, Mohammad Javad (2002). Multicriteria Models of Decision-making. Tehran University Publication.

3. Alaimo, Peter \& Amanda-Lynn Marshall (2010) "Useful Products from Complex Starting Materials: Common Chemicals from Biomass Feed stocks” Chemistry - A European Journal 15 4970-4980.

4. Azadfallah, M., \&Azizi, M. (2016). A new approach in group decision-making based on pairwise comparisons. Journal for International Business and Entrepreneurship Development, 8(2), 159-165.

5. Azadi, M., Jafarian, M., Saen, R. F., \& Mirhedayatian, S. M. (2015). A new fuzzy DEA model for evaluation of efficiency and effectiveness of suppliers in sustainable supply chain management context. Computers \& Operations Research, 54, 274-285.

6. Buchert, T., Neugebauer, S., Schenker, S., Lindow, K., \& Stark, R. (2015). Multi-criteria decision making as a tool for sustainable product development-Benefits and obstacles. Procedia CIRP, 26, 70-75.

7. Lam, J. S. L., \& Dai, J. (2015). Environmental sustainability of logistics service provider: an ANP-QFD approach. The International Journal of Logistics Management, 26(2), 313-333.

8. Liu, G., E. D. Larson, R. H. Williams, T. G. Kreutz and X. Guo (2011). "Making fischer-tropsch fuels and electricity from coal and biomass: Performance and cost analysis." Energy \& Fuels 25: 415-437.

9. Mario Cozzi, Mauro Viccaro, Francesco Di Napoli, Claudio Fagarazzi, Alessandro Tirinnanzi, Severino Romano (2015),. "A spatial analysis model to assess the feasibility of short rotation forestry fertigated with urban wastewater: Basilicata region case study". Agricultural Water Management 159, 185-196.

10. Martijn Bouwknegt, Katharina Verhaelen, Artur Rzeżutka, Iwona Kozyra, Leena Maunula, Carl-Henrik von Bonsdorff, Apostolos Vantarakis, Petros Kokkinos, Tamas Petrovic, Sava Lazic, Ivo Pavlik, Petra Vasickova, 
Kris A.Willems, Arie H. Havelaar, Saskia A. Rutjes, Ana Maria de Roda Husman (2015),. "Quantitative farm-to-fork risk assessment model for norovirus and hepatitis A virus in European leafy green vegetable and berry fruit supply chains". International Journal of Food Microbiology 198, 50-58

11. Mulbry, W., Kangas, P., \& Kondrad, S. (2010). Toward scrubbing the bay: Nutrient removal using small algal turf scrubbers on Chesapeake Bay tributaries. Ecological Engineering, 36(4), 536-541.

12. Pishvaee, M.S., \& Razmi, J. (2012). "Environmental supply chain network design using multi-objective fuzzy mathematical programming". Applied Mathematical Modelling, 36, 8, 3433-3446.

13. Razmi, Jafar (2013). Green Supply Chain (Planning, Programming, Establishment and Evaluation). Gazvin IAU Publications.

14. Wei Zhang, Yufeng Ma, Chunpeng Wang, Shouhai Li, Mingming Zhang, Fuxiang Chu (2013), "Preparation and properties of lignin-phenol-formaldehyde resins based on different biorefinery residues of agricultural biomass". Industrial Crops and Products 43, 326- 333.

15. Wibisono, D., \& Khan, M. K. (2016). Performance Measurement System for a Manufacturing Environment: KB/GAP/AHP Approach. International Journal of Robotics and Mechatronics, 2(2), 65-76.

16. Wu, G.C., J.H., Ding, P.S., Chen .2012. The effects of GSCM drivers and institutional pressure on GSCM practices in Taiwan's textile and apparel industry, International Journal Production Economics, Vol. 135, pp. 618-636

17. Yongming, H., Peixuan, D., Junji, C., \& Posmentier, E. S. (2006). Multivariate analysis of heavy metal contamination in urban dusts of Xi' an, Central China. Science of the total environment, 355(1), 176-186.

18. Zailani, S., Govindan, K., Iranmanesh, M., Shaharudin, M. R., \& Chong, Y. S. (2015). Green innovation adoption in automotive supply chain: the Malaysian case. Journal of Cleaner Production, 108, 1115-1122. 